\title{
Study on the Training Mode of Hotel Management Based on Market Demand
}

\author{
Shuangfan Song \\ Hubei University of Science and Technology, Xianning, China
}

Keywords: Market demand, Hotel management, Managerial talent, Training mode

\begin{abstract}
How to cultivate hotel management personnel and how to build up training mode are the key problems in hotel management. Although these problems were studied before, most of them only stayed in the level of theoretical knowledge and did not give any concrete measures and methods. Based on the structural changes of the market demand, this paper resets the personnel training objectives of hotel management major and studies the training mode of hotel management specialty technical talent management from three aspects: curriculum mode, teaching mode and training mode.
\end{abstract}

\section{Introduction}

In today's world, the rapid economic development, government support for tourism is also increasing, under which the tourism industry has become a pillar industry of national economy, the hotel industry as one of the three pillars of tourism, has been rapid development of.

The hotel has its own special industry character. First of all, as a service industry, the nature of work is to provide services to guests. Most hotel professional graduates enter the hotel business and start from the grassroots level. They have direct contact with customers and face complicated interpersonal relationships. Many graduates find it hard to get fast Second, in the subconscious of society, they cannot escape the old concepts of low-level occupations for thousands of years, leaving the graduates with less confidence in the industry and eventually causing more mobility of employees and fewer professionals in the domestic hotel industry [1]. As the cradle of cultivating talents, universities and colleges are mushroomed in many colleges and universities all over the country. It seems that the management and training of hotel managers have been solved. However, in fact, the proportion of hotel majors losing from this profession has been continuously rising year after year. The hotel talent gap is still huge. The reason for this is due in large part to students' work content and industries [1]. There is a big difference between understanding and reality, and the difference has not been properly resolved, the direct result shown is the graduates to the hotel after work high "loss" phenomenon.

\section{The Existing problems of hotel management personnel training}

\subsection{Hotel management personnel training target orientation misleading}

Since the establishment of hotel management professional, many colleges and universities have been positioning the talent training as a hotel senior management personnel, high professional goal positioning misleading students in the heart of the industry, resulting in many graduates in the career "eye high" and unsteady state of mind [2]. Most graduates think they are learning management professional, they should go to the hotel to do management work, do not start from the grassroots, the result should be waiters, a huge gap, so that they leave the hotel, choose other industries.

\subsection{Hotel management professional and curriculum more traditional}

Hotel management professional development in China is in its infancy, many colleges and universities hotel management professional is also hasty, some hotel management teachers also lack of rich professional experience and solid professional knowledge, which led to many schools in the hotel management professional courses Set on the use of copying copy mode, the textbook purchase, the lack of standards, and some teachers simply make their own textbooks, set up courses, shutting the door to their own teaching plan curriculum and assessment standards, making personnel training 
and international The standard deviation is very big.

\subsection{Hotel management professional teaching simpler}

In the teaching process, many schools are still based on the traditional theory teaching, even if the practice class is also a go-go, as the domestic hotel management basically no own internship hotel, but more is to expand and social hotel union School mode, the model of cooperation between the school and the hotel inter-disciplinary gap between the larger interest between the two points is not uniform: the hotel hopes to receive free, cheap labor, college wishful thinking that students can learn a lot through internship things [1]. The result is that many students did not achieve the improvement of skills and management through internship. How to do a good job in school-enterprise cooperation and reach a win-win situation is a problem that colleges and the hotel industry need to jointly solve.

\subsection{Graduate feedback mechanism not established}

Graduates into the community, contact with his alma mater interrupted, the problems encountered in the work cannot be solved, there is no relevant channels of communication flu, so some students can only choose to go abroad to study hotel management, by accepting the industry-renowned professional hotel School system training and internships to seek better development on the career path, while a larger proportion of graduates choose to quit their jobs and seek alternative solutions. Due to lack of feedback mechanism, schools have not found any potential professionals to cultivate a crisis.

\section{Correct orientation of Training Hotel Management Personnel}

\subsection{Structural Change of Market Demand for Hotel Talents in China}

In the early stage of reform and opening up, the hotel industry in China was in the seller's market. Standardized operation and standardized management were the top priorities of the time. Service personnel with good service awareness and operational skills were the most urgent needs. After nearly 30 years of development, the development of China's hotel industry, the problems faced and the structure of the demand for talent have undergone significant changes. Hotel management has greatly improved the level of so-called standardized management is no longer a problem [2]. The challenge facing the hotel industry today is how to market segments, provide personalized service products, how to establish brand characteristics, realize group management, and how to improve management informatization and internationalization. Hotel management decision-making, ranging from development strategy, investment planning, small service product design, room price determination, etc., must be based on scientific data analysis, rather than alone based on experience to decide. The hotel industry's urgent need for professionals is no longer a skilled grassroots service operator, but rather:

First, familiar with the operation of international hotel management and laws and regulations, with international strategic vision and rich management experience in senior management personnel;

Second, it has a good professionalism and professional background, with strong language communication, organization and coordination and business development capabilities, not only mastered a certain level of first-line service operation skills, but also good at information technology and organizational planning, to conduct on-site command and coordination , Understand market research, mathematical statistics, revenue analysis and service product design, with strong management of mental skills and innovative thinking of the technical management of complex talents [2].

\subsection{Target Selection of Hotel Management Talents Training}

Hotel Management higher vocational education belongs to higher education, of course, is also different from secondary vocational education. Skilled talented people mainly rely on the movement skills for production operations, while skilled personnel use mental skills to complete the production work. Technical personnel not only have to have a certain production and operation skills, but also be good at technology (or management) intentions into physical entities (or management processes and 
results), to be able to conduct technical guidance at the production site, organize and coordinate the production of Practical problems, the production information can be analyzed, processed, to improve technology and process, improve product design. Higher education in the international academic level is not limited to specialist, therefore, higher vocational education in hotel management professionals, equivalent to "college cultural base + knowledge of technical secondary school + technical school operating ability" approach is to vocational Education has been simplified [3].

In fact, basic hotel service operations almost no technical and knowledge content. And with the social development and the improvement of people's living standards, many service-level things have become explicit knowledge and have lost the necessity of classroom teaching. If the goal of cultivating talents in higher vocational education stays at the level of service skills, it neither meets the realistic requirements of the development of China's hotel industry nor is it similar to secondary vocational education and is a waste of educational resources. In addition, China's current practice of restricting higher vocational education to college level, in essence, gives greater flexibility to the (college) level boundaries of higher vocational education in hotel management. Targeting the training objectives at the level of service operations is completely into Misunderstanding [3]. Technical management of advanced compound talents training is the real estate management professional goal of higher vocational education.

\section{Hospitality Management Talent Training Model Based on Market Demand}

\subsection{Strengthen the school and the market right}

The purpose of school training students is to deliver more outstanding talents for the enterprise. If you want to achieve this goal, the school must go into the enterprise and grasp the development direction and development needs of the enterprise. Therefore, the school should strengthen its research work on the hotel. First of all, the school should formulate the hotel research periodic table, the appropriate shortening of the research cycle, timely grasp of the development of the hotel industry, new developments and new ideas. Secondly, the hotel research work should have a certain degree of universality. Students may enter different kinds of hotel work after graduation [3]. If the research work of the school is not enough to stay in the star-rated hotel, the school should strengthen the different Type of hotel research, to expand the scope of research, to help students enter different hotel work. In addition, schools should strengthen exchanges with enterprises and sincerely invite hotel staff to put forward valuable opinions on the school's teaching plan and improve the operability and practical value of the teaching plan.

\subsection{Strengthen the construction of teachers}

1) The establishment of double-qualified teachers. On the one hand, encourage teachers to go to the hotel to carry out post-graduate training, through the guidance of the research in the hotel, so that teachers in the hotel industry more in-depth understanding; the other hand hired rich experience in hotel management personnel to work in schools and increase policy and funding Support for students, so as to hire students have rich hotel experience "double teacher" to provide protection [4]. 2) Broaden the channels of teacher introduction. First, the school can choose to send some young teachers to foreign hotel management institutes or hotel groups for vocational skills and teaching level training; Second, the school can introduce some high-level management personnel from the hotel, so that the school teaching theory and practice The combination. Third, schools can invite the best staff at all levels of the hotel to give lectures in schools. 3) Encourage teachers to innovate teaching courses. Teachers' teaching should be changed with the development of the times, it should be continuous innovation, and especially teachers of hotel management should pay more attention to the innovation of teaching curriculum [4]. In the process of teaching, teachers should strengthen the innovation of teaching methods and teaching methods, strengthen the application of multimedia technology, display pictures and texts to students and so on. 


\subsection{Curriculum should be with the international standards}

According to the development needs of the hotel industry, the establishment of professional main courses as well as some popular courses with strong practicability should be constantly updated. In the setting of course system above, the Swiss Institute of Hotel Management Lausanne follow the pace of the times, to meet market demand, highlighting the professional characteristics of the course is divided into three categories: theoretical courses, practical courses and language courses, it is worth learning from [4].

\subsection{Adhere to the brain and use the principle of combining learning}

During the communication with graduates, students generally feel that when they come to society, they know the importance of school education. It is impossible for schools to set goals, cherish time and learn well. Now they want to go to the classroom again. This is a common problem existing in most vocational colleges. Students are not clear about the nature of their profession at first, then they do not understand the needs of society, and they show no goals during their studies in colleges and universities [5]. They have not paid enough attention to specialized courses and language courses, the lack of hard study spirit, the majority of students in school goals turned out to be able to pass the final exam. Under such circumstances, it is very hard for students to study hard and learn. This is also the main reason students cannot do the hotel work. To solve the above problems can start from the following two aspects.

\subsection{Cultivate students' professional awareness and improve overall quality}

Most of the graduates of hotels use first-line service, which is also in accordance with the general rules of employers. Many students quit or switched jobs at the beginning of their internship or at the beginning because of the hard work of the hotel. This requires schools in the usual teaching, to strengthen students' professional ideological education. When students just enter the professional study, they must tell them the essential characteristics of hotel work. To help students make ideological preparations as soon as possible, to avoid students in the process of internship and employment "Occupy good eyes" problem, and strengthen the sense of professional responsibility. In particular, as a professional teacher, we should contact the actual case of the hotel in the usual teaching process; subtly cultivate students' professional "loyalty", emphasizing the importance of basic work. In the school teaching to increase language classes and psychology courses, students develop a correct outlook on life, values; teach students basic interpersonal skills [5]. Students during school more to carry out some social activities encourage students to actively participate in, training students to solve problems, with people's ability to lay the foundation for future work and life.

\subsection{Establish graduate employment feedback, return education, on-the-job training mechanism}

Graduates into the hotel after work, due to the role of change, there will certainly be a lot of incommensurate, and some students will feel "book to use less time hate" feeling, so they will be in urgent need to be able to return to school charging at present, many colleges and universities in our country generally pay little attention to the graduates who have employed and do not have the awareness of providing planning for the hotel career of graduates [6]. In this respect, we can provide regular lectures, International advanced hotels hold short-term training courses, undertaking professional certification exams and many other ways to enhance social education and service capabilities so that graduates can still enjoy their alma mater, hotel management professional related resources, but also help to some graduates My heart to divert, from the side to reduce the high rate of hotel management professionals wastage.

\subsection{Hotel emphasis on staff training}

The hotel can improve the quality of staff, work efficiency and professional ethics through training, and cultivate the ability of continuous learning, so as to realize the overall goal of people-oriented optimization and establish a dynamic training system of "fullness, low priority, high viewpoint and 
optimization" [6]. And each type of training projects should be included in the training plan, should be organized and implemented on a planned basis; the implementation process should be feasible.

When employees take training as a good opportunity for self-development and self-improvement, they will not change jobs frequently due to lack of organizational support. On the one hand, a wide range of training helps employees feel more sense of belonging and enjoyment. Employees like the challenge of training, reducing the annoyance and resentment caused by repeating the same work over a long period of time [6]. On the other hand, a multi-skill, efficiency greatly improved, thus saving labor capital.

\subsection{Hotel perfect examination and promotion mechanism}

A survey of nearly 10,000 hotel practitioners showed that about two-thirds of the employees left the hotel, especially good ones, for not being satisfied with the future or not being promoted. In order to avoid this phenomenon, the hotel should improve the assessment and promotion mechanism. First, to develop a unified assessment standards, the hotel's assessment standards and service quality standards are unified, not only based on business performance assessment; two should allow employees to understand the performance assessment of the content and procedures for staff to monitor their performance in real time At the same time, managers should also brainstorm ideas and promptly improve the assessment work; three pairs of outstanding employees to give recognition, rewards and promotion opportunities; Fourth, adhere to the principle of fair assessment, so that employees feel their contribution has been fair assessment, So that employees may see their own future. Only an impartial company can attract good people to develop a loyal employee. When the hotel vacancy occurs, first of all should be open recruitment within the hotel supplement, the store cannot be supplemented from the store to recruit. By giving employees the sense of opportunity to advance as long as they work hard, the morale and loyalty of their employees will be greatly enhanced. In the meantime, the hotel has set up several different levels for each person's position, and outstanding service personnel may increase their salary through the promotion level without having to leave the service front line [7].

\subsection{The hotel establishes a fair competition salary system}

In the treatment of employees, the hotel first pay the employees should basically be above or equal to the industry average wage level; In the reward program, based on their own business performance decisions, try to shorten the higher authorities to declare the approval process, for independent decision-making Bonus and compensation system of the decision [7]. Incentives are varied and material is not the only form of encouragement. For many employees, it is even more important for them to be motivated, develop their future, and improve their positions and training opportunities.

\section{Conclusions}

China's hotel management professionals to adapt to the market to adapt to the international hotel industry, to be done still many efforts to promote the sustainable development of China's hotel industry needs, with the times, innovation, to explore the hotel management professional Talents training is imperative. The efforts and attempts in this field will be beneficial to improve the personnel training level of the hotel industry in our country, and provide more qualified and better professionals for the hotel management industry.

\section{References}

[1] Z.G. Wang, Opportunities and Development of China's Tourist Hotels, Beijing: China Science and Technology Information, 2005, pp.10, pp.150 151 .

[2] Z.B. Tong, Modern hotel management ideas and competitive strategy, Guangzhou: Guangdong Tourism Press, 2014, vol.10, pp. 19-22.

[3] X.R. Wang, Hotel Human Resources Development and Management, Guangdong Science and 
Technology, 2009, vol.22, pp.5-6.

[4] Y.T. Chen, Modern hotel's new training model, Talent development, 2004, vol.8, pp. 43-44

[5] J.J Min, Talent Cultivation Model and Its Connotation Analysis, Journal of Wuhan Polytechnic, 2005, vol.6, pp. $17 \sim 24$

[6] J.M. Wan, International Comparison and Enlightenment of Higher Vocational Talent Training Mode, China Vocational and Technical Education, 2004, vol.14, pp.58 60

[7] G.Q. Zheng, Vocational Education Talents Training Mode Overview, Vocational Education Forum, 2005, vol.8, pp.20 23 